OPEN ACCESS

Edited by:

Jose R. Pineda,

University of the Basque Country,

Spain

Reviewed by:

Rasime Kalkan,

Near East University, Cyprus

Gloria Perazzoli,

University of Almeria, Spain

*Correspondence:

Jizong Zhao

zhaojizong@bjtth.org

Specialty section:

This article was submitted to

Neuro-Oncology and

Neurosurgical Oncology,

a section of the journal

Frontiers in Oncology

Received: 09 March 2021 Accepted: 29 April 2021

Published: 13 May 2021

Citation:

Li J, Wang W, Wang J, Cao Y, Wang S and Zhao J (2021) Viral

Gene Therapy for Glioblastoma Multiforme: A Promising Hope for the Current Dilemma.

Front. Oncol. 11:678226. doi: 10.3389/fonc.2021.678226

\section{Viral Gene Therapy for Glioblastoma Multiforme: A Promising Hope for the Current Dilemma}

\author{
Junsheng $\mathrm{Li}^{1,2,3,4,5}$, Wen Wang ${ }^{1,2,3,4,5}$, Jia Wang ${ }^{1,2,3,4,5}$, Yong Cao ${ }^{1,2,3,4,5}$, \\ Shuo Wang ${ }^{1,2,3,4,5}$ and Jizong Zhao ${ }^{1,2,3,4,5,6^{*}}$
}

${ }^{1}$ Department of Neurosurgery, Beijing Tiantan Hospital, Capital Medical University, Beijing, China, ${ }^{2}$ China National Clinical Research Center for Neurological Diseases, Beijing, China, ${ }^{3}$ Center of Stroke, Beijing Institute for Brain Disorders, Beijing, China, ${ }^{4}$ Beijing Key Laboratory of Translational Medicine for Cerebrovascular Disease, Beijing, China, ${ }^{5}$ Beijing Translational Engineering Center for 3D Printer in Clinical Neuroscience, Beijing, China, ${ }^{6}$ Savaid Medical School, University of the Chinese Academy of Sciences, Beijing, China

Glioblastoma multiforme (GBM), as one of the most common malignant brain tumors, was limited in its treatment effectiveness with current options. Its invasive and infiltrative features led to tumor recurrence and poor prognosis. Effective treatment and survival improvement have always been a challenge. With the exploration of genetic mutations and molecular pathways in neuro-oncology, gene therapy is becoming a promising therapeutic approach. Therapeutic genes are delivered into target cells with viral vectors to act specific antitumor effects, which can be used in gene delivery, play an oncolysis effect, and induce host immune response. The application of engineering technology makes the virus vector used in genetics a more prospective future. Recent advances in viral gene therapy offer hope for treating brain tumors. In this review, we discuss the types and designs of viruses as well as their study progress and potential applications in the treatment of GBM. Although still under research, viral gene therapy is promising to be a new therapeutic approach for GBM treatment in the future.

Keywords: gene therapy, viral therapy, glioblastoma multiforme, viral vector, treatment strategy

\section{INTRODUCTION}

Glioblastoma multiforme (GBM) is one of the most common primary brain tumors in adults $(1,2)$, mainly derived from astrocytes $(3,4)$. The World Health Organization (WHO) classification in 2016 defined GBM as grade IV, which leads to a high degree of malignancy and mortality. The current standard treatment for GBM includes maximum surgical resection, radiotherapy, and chemotherapy (5-7). However, the complete resection of GBM has been challenging due to the invasive growth pattern and the functional area involvement. It has been almost inevitable that the tumor-infiltrating parenchyma tissue eventually relapsed even after surgical resection $(8,9)$. The resistance to chemotherapy drug temozolomide (TMZ) was mainly caused by O6-methylguanineDNA methyltransferase over-expression, mismatch repair and base excision repair (10-12). The molecules mediated GBM chemoresistance, including P-glycoprotein, multidrug-resistance protein transporters, and DNA repair enzymes (13). Furthermore, the inefficient delivery across the 
blood-brain barrier (BBB) limited the entry of therapeutic drugs into the central nervous system (CNS) (14-16). Glioblastoma stem cells supported tumor self-renewal which contributed to GBM resistance to radiotherapy (17-19). So even with standard treatment, the outcome of patients with GBM was still very poor. The median survival of patients diagnosed with GBM was just about 15 months (20-22). The clinical use of additional therapies, including local adjuvant therapy with Carmustine wafers and tumor-angiogenesis inhibition with Bevacizumab, were tried to improve the outcome (23-26). However, the survival rate was still less than $5 \%$ within five years of diagnosis $(27,28)$.

Therefore, the application of new treatment methods to get rid of the limitations of conventional treatment has been necessary. Growing evidence has proved that tumor is a kind of genetic disease $(29,30)$. With the exploration in the treatment of other diseases, viral gene therapy has brought hope for the treatment of GBM (31-33). Both wild-type viruses and engineered viruses could be used for viral gene therapy. Nonlytic viruses were used for gene therapy and lytic viruses exert anti-tumor effects by inducing tumor cell lysis (34). Moreover, the lytic viruses exposed GBM antigens to the host immune system which stimulated a specific immune response to tumor cells (35). The natural sensitivity of GBM cells to virus infection has made viral therapy a promising prospect. The viral vectors were designed according to the characteristic of target cells, the size of therapeutic gene, and the ability of long-term gene expression. In this review, we will focus on the types of viral vectors and demonstrate the versatility of gene therapy for GBM treatment. In this review, we will focus on the types of viral vectors (Table 1) and demonstrate the versatility of gene therapy for GBM treatment.

\section{VIRAL VECTORS}

\section{Retrovirus}

Because of the special biological characteristics, retrovirus vectors were first attempted in gene therapy for glioma. Replicating retroviral vectors were able to deliver the prodrug activator genes, which were also called suicide genes, into tumor cells and integrate into host genomes $(36,37)$. When a prodrug was given, the protein expressed by the gene could convert the non-toxic drug into a cytotoxic substance, which led to GBM cell death (38). Even as tumor cells escape the killing of cytotoxic drugs, they could also be used as an integrated retrovirus set and continue to play a role in the events of GBM recurrence (39). Therefore, this method was also known as "suicide gene therapy". In the initial clinical trial, the therapeutic effect of retroviral vectors encoding herpes simplex virus thymidine kinase (HSV-tk) on malignant brain tumors was evaluated. The researchers found that HSV-tk could convert ganciclovir (GCV) into an active form of GCV triphosphate, which inhibited DNA replication and cell division in tumor cells, resulting in an

TABLE 1 | Modifications and mechanisms of the viral vectors used for GBM gene therapy.

\begin{tabular}{|c|c|c|c|}
\hline Viral vector & Agent & Modification & Mechanism \\
\hline \multirow[t]{2}{*}{ Retrovirus } & HSV-tk & suicide gene therapy, thymidine kinase (TK) gene transfer & $\begin{array}{l}\text { converting ganciclovir (GCV) into active form GCV } \\
\text { triphosphate }\end{array}$ \\
\hline & TOCA511 & suicide gene therapy, cytosine deaminase (CD) gene transfer & $\begin{array}{l}\text { converting 5-fluorocytosine (5-FC) into active antineoplastic } \\
5 \text {-fluorouracil (5-FU) }\end{array}$ \\
\hline \multirow[t]{3}{*}{ Lentivirus } & $\begin{array}{l}\text { shRNA-lentivirus } \\
\text { sh-SirT1 lentivirus }\end{array}$ & $\begin{array}{l}\text { sh-Bcl2 and S-TRAIL transfer } \\
\text { sh-SirT1 transfer }\end{array}$ & $\begin{array}{l}\text { down-regulating Bcl-2 and inducing S-TRAIL expression } \\
\text { silencing SirT1 in CD133+ cells to improve radiotherapeutic } \\
\text { sensitivity }\end{array}$ \\
\hline & miR-100 lentivirus & miR-100 transfer & $\begin{array}{l}\text { regulating FGFR3 to inhibit tumor growth and increase } \\
\text { sensitivity to chemotherapy }\end{array}$ \\
\hline & $\begin{array}{l}\text { GAS1-PTEN } \\
\text { lentivirus }\end{array}$ & $\begin{array}{l}\text { growth arrest specific } 1 \text { (GAS1) and phosphatase and tensin } \\
\text { homolog (PTEN) gene transfer }\end{array}$ & $\begin{array}{l}\text { expressing GAS1 and PTEN equally to perform } \\
\text { superimposed anti-tumor effect }\end{array}$ \\
\hline \multirow[t]{2}{*}{ Adenovirus } & ONYX-015 & E1B gene deletion & replicating in p53 pathway altered tumor cells \\
\hline & Delta-24 & $\begin{array}{l}\text { E1A gene partial deletion, } \\
\text { Delta-24 RGD: Arg- Gly-Asp peptide sequence incorporation }\end{array}$ & $\begin{array}{l}\text { replicating in Rb/p16 tumor suppressor pathway defective } \\
\text { GBM cells } \\
\text { Delta-24 RGD: expressing } \alpha \text { integrins to enhance infectivity }\end{array}$ \\
\hline \multirow{4}{*}{$\begin{array}{l}\text { Herpes } \\
\text { simplex virus }\end{array}$} & HSV1716 & RL1 gene $(\gamma 34.5)$ loci deletion & targeting cells with defects in PKR pathway \\
\hline & $\mathrm{C} 134$ & $\begin{array}{l}\text { RL1 gene }(\gamma 34.5) \text { loci deletion, } \\
\text { human cytomegalovirus IRS1 gene transfer }\end{array}$ & expressing IRS1 protein to enhance replication \\
\hline & G207 & RL1 $(\gamma 34.5)$ and UL39 gene deletion & inhibiting viral replication in non-dividing cells \\
\hline & rQNestin34.5v.2 & $\begin{array}{l}\text { RL1 gene }(\gamma 34.5) \text { loci deletion, } \\
\text { RL1 gene under control of nestin promoter. }\end{array}$ & replicating in PKR-deficient, nestin-positive tumor cells \\
\hline \multirow[t]{4}{*}{ Oncolytic virus } & $\begin{array}{l}\text { Pelareorep } \\
\text { (REOLYSIN) }\end{array}$ & wild-type reovirus & replicating specifically in Ras pathway activated tumor cells \\
\hline & TG6002 & $\begin{array}{l}\text { ribonucleotide reductase genes deletion vaccinia, } \\
\text { suicide gene therapy, FCU1 gene transfer }\end{array}$ & direct oncolysis effect and prodrug conversion \\
\hline & $\mathrm{H}-1 \mathrm{PV}$ & wild-type parvovirus & $\begin{array}{l}\text { clathrin-mediated endocytosis, DNA damage response, and } \\
\text { cell-cycle arrest }\end{array}$ \\
\hline & PVS-RIPO & poliovirus-rhinovirus chimera & restrict replicating in CD155-expressing tumor cells \\
\hline
\end{tabular}


anti-tumor effect (40). However, the results also indicated the limitations in transfection inefficiency of retroviral vectors was inefficient (41).

Retroviral vector TOCA511 has been used to deliver cytosine deaminase (CD) gene into tumor cells (42). CD enzyme converted the prodrug 5-fluorocytosine (5-FC) to active antineoplastic 5-fluorouracil (5-FU) which caused the death of tumor cells. The preclinical studies observed that TOCA511 did not lead to widespread or uncontrolled replication, which proved the safety of TOCA511 treatment. The safety and activity of TOCA511 were further supported by molecular analyses (43). Moreover, another study found that in addition to direct cytotoxic effects, TOCA511 could also be used as a radiosensitizing agent (44). TOCA511 could increase the intratumor concentration of 5-FU and induce $\mathrm{T}$ cell-mediated antitumor immunity $(45,46)$. TOCA 511 has been shown to be safe and provide a significant survival benefit in the clinical trial (47). Recent results from the Phase III clinical trial showed that TOCA511 treatment significantly improved survival in patients with two or more recurrences (48).

\section{Lentivirus}

Lentiviruses belonged to the retroviridae family $(49,50)$. Exogenous genes or shRNAs could be effectively integrated into the genomes of dividing or non-dividing cells to achieve the effect of persistent expression of the target sequence (51). Compared with retroviral vectors, lentiviral vectors were more stable and less prone to insertion mutation. The active transportation of pre-integration complex through the nucleopore was the unique mechanism of lentiviral vectors (52). Researchers constructed a lentiviral vector expressing shRNA to downregulate $\mathrm{Bcl}-2$ and S-TRAIL to induce apoptosis in glioma cells. The result showed that lentivirusmediated apoptosis resulted in an increase in the expression of activated caspase- 3 and caspase-7, which accelerated the apoptosis of tumor cells (53). The transfection of target genes by lentiviral vectors could improve sensitivity of GBM to radiotherapy. The $\mathrm{CD}_{133^{+}}$cells in GBM were resistant to radiotherapy. A study down-regulated the expression of sirtuin 1(SirT1) in $\mathrm{CD}_{133^{+}}$by a lentiviral vector expressing shRNA (shSirT1). The results showed that the silence of SirT1 significantly enhanced the inhibition of tumor growth by radiotherapy and improved the mean survival rate of GBM (54).

Specific miRNAs were proved to be associated with the increase of proliferation, invasiveness, angiogenesis, and apoptosis resistance in GBM. A study has shown that with the transfection of lentiviral vectors, the overexpression of miR-100 significantly inhibited the growth and migration of GBM, and increased the sensitivity to chemotherapy. And the delivered miR-100 played an anti-tumor effect on GBM by regulating FGFR3 directly (55). The latest genome editing technology could also be used for GBM treatment by lentiviral vector transfection. It has shown that editing the sequence of vascular laminin-411 overexpressed in GBM could suppress tumor growth and improve survival of GBM (56). Researchers constructed lentiviral vectors with an equal expression of growth arrest specific 1 (GAS1) and phosphatase and tensin homolog
(PTEN) via the versatility of expression cassettes allocation. Both of the transgenes were regulated by the same promoter. The result showed that the anti-tumor effect of GAS1 could be superimposed with the inhibitory effect of PTEN on Akt pathway, and this could significantly inhibit the growth of GBM (57).

\section{Adenovirus}

Adenovirus is a non-enveloped double-stranded DNA virus (58, 59). Adenoviruses selected for gene therapy were serotypes 2 and 5 (60). Adenoviral vectors used coxsackie-adenovirus receptor (CAR) to mediate cell tropism and internalize adenovirus vectors by the interactions between penton protein and host cell surface integrins (61-63). After endocytosis into the tumor cells, adenoviruses did not integrate into the host genome and remained episomal while gene expression (64).

The E1 and E3 regions of adenovirus genome were conventionally deleted to eliminate the expression-related toxicity by adenovirus infection. The latest generation of adenoviral vectors could minimize the anti-adenovirus immune response by removing all the endogenous virus coding regions to induce more stable transgene expression (65). The deficiency of non-replicative adenoviruses was that episomes might be diluted due to cell division, resulting in a rapid decline in transgene expression. Conditional replication adenoviruses, as tumor-specific agents, were designed to selectively replicate within and kill the tumor cells (66). Moreover, the replicated transgenes could spread the therapeutic effect to other neighboring tumor cells. The genetically modified adenovirus ONYX-015 was a recombinant chimeric Ad2 and Ad5 vector with selective replication ability. The protein encoded by adenovirus E1B gene interacted with tumor suppressor p53 and the transcriptional activity was blocked (67). Due to the decreased expression of p53 in GBM, ONYX-015 was able to replicate effectively. Previous studies showed that ONYX-015 administration was safe and effective (68). And the phase I clinical trial has shown that no serious adverse events were observed in patients treated with ONYX-015 and ONYX-015 therapy could significantly inhibit tumor growth (69).

Delta-24 was designed to selectively replicate in cells deficient in the Rb/p16 tumor suppressor pathway. The deletion of retinoblastoma $(\mathrm{Rb})$ binding domain fragment in E1A gene inhibited the interaction between $\mathrm{E} 1 \mathrm{~A}$ and $\mathrm{Rb}$. $\mathrm{Rb}$ protein negatively regulates cell growth by blocking E2F. Rb/p16 tumor suppressor pathway deficiency likely occurred in GBM cells, which made it possible for Delta-24 selective replication in GBM cells but not in the normal cells (70). Furthermore, it was difficult for adenoviral vectors transfection due to the poor expression of CAR in tumor cells, which reduced the therapeutic effect. By mortifying an Arg- Gly-Asp peptide sequence in the HI loop of the fiber, the vectors were allowed to bind $\alpha \mathrm{v}$ integrins to enter the tumor cells, thus enhancing the infectivity of the virus (71). Delta-24 and its modified versions have shown encouraging results in clinical trials (72).

\section{Herpes Simplex Virus}

Herpes simplex viral vectors used for gene therapy were mainly modified from Herpes Simplex virus type 1 (HSV-1), an 
enveloped double-stranded DNA virus (73). Due to the neurotropic nature, HSV vectors are attractive for gene transduction in central nervous system tumors. The $152 \mathrm{kbp}$ genome length made it possible to carry a sufficient payload (68).

RL1 gene $(\gamma 34.5)$ was a necessary gene for effective replication of HSV. RL1 gene encodes The Infected Cell Protein 34.5 (ICP34.5), also known as Neurovirulence factor ICP34.5, was encoded by RL1. Phosphorylation of translation initiation factor eIF2 $\alpha$ by protein kinase R (PKR) inhibited the translation process and blocked the production of viral proteins. Moreover, PKR could activate transcription factor NF- $\kappa B$ by inducing the degradation of negative regulator $I \kappa B$ to stimulate the antiviral immune response. ICP34.5 reversed this process by activating phosphatase-1 $\alpha$ (74). The PKR pathway was often inhibited in GBM, so it did not restrict the replication of HSV vectors with the modification of ICP 34.5. For example, the recombinant vector HSV1716 removed both copies of RL1 to allow its selective replication in tumor cells (75). Clinical studies have proved that HSV-1716 can effectively improve the survival of patients $(76,77)$. C134 vectors deleted RL1 gene and inserted human cytomegalovirus IRS1 gene to enhance replication (78).

Another important gene UL39 encoded the large subunit of ribonucleotide reductase (RR), also known as ICP6. This protein converts ribonucleotide into deoxyribonucleotide allowing viral DNA replication, and the UL39-deficient vectors were unable to replicate in non-dividing cells. However, the host ribonucleotide reductase could compensate for the function loss of viral $R R$ in dividing cells. Combining the two mechanisms above, the deletion of RL1 gene in G207 allowed the virus to target GBM cells, and the mutation in UL39 gene eliminated the replication in normal non-dividing cells (79). The result of the clinical studies has shown the safety of G207 in GBM treatment, and the favorable therapeutic effect of the combination with G207 and radiotherapy in recurrent GBM treatment $(80,81)$. Due to the specific up-regulation of nestin promoter in gliomas, rQNestin34.5v.2 vectors were designed within an insertion with a copy of RL1 gene under the transcriptional control of nestin promoter. The combination of the vectors and cyclophosphamide was proved to increase virus replication in tumors and improve the survival rate of patients (82).

\section{Oncolytic Virus}

Oncolytic viruses had dual anti-tumor effects, which not only destroyed tumor cells directly but activated tumor-specific immune response. Current clinical trials have demonstrated the feasibility of OV-specific tumor infection. By selective transfection and replication $(83,84)$, tumor cell lysis was induced without damage to normal cells. Furthermore, oncolytic viruses were also able to infect tumor vascular endothelial cells, inhibit tumor-related angiogenesis, and cause hypoxic death of tumor cells (85). Meanwhile, oncolytic viruses induced systemic anti-tumor immunity by releasing tumorassociated antigens (86).

In addition to wild-type viruses, engineered viruses could also be used as oncolytic viruses, including reovirus, vaccinia virus, parvovirus, poliovirus, vaccinia virus, Newcastle disease virus, etc. And the anti-tumor immunity could be further enhanced by encoding cytokines, chemokines, and tumor-associated antigens (87). Currently, types of viruses have been involved in clinical trials to verify the safety and therapeutic effectiveness. Reovirus was a non-enveloped wild-type oncolytic virus with doublestranded RNA genome. Reovirus Pelareorep (REOLYSIN) could replicate specifically in Ras pathway activated tumor cells (88). In the phase I clinical trial, no treatment-related adverse reactions after intratumoral injection of reovirus were observed (89). Reovirus therapy could lead to tumor leukocyte infiltration and an increase in the expression of IFN, caspase 3, and PD-L1 (90). As an enveloped double-stranded DNA virus, the vaccinia virus did not rely on cell receptors, but membrane fusion to enter cells. Its rapid replication cycle and strong ability of intercellular transmission made it a promising candidate for viral therapy (91). TG6002 was modified from vaccinia virus, which was designed as a combination of direct oncolysis effect and prodrug conversion function. It mainly replicated in tumor cells and transformed 5-FC into 5-FU. Its safety and oncolytic activity have been confirmed in a large number of preclinical studies (68). Parvovirus was a single-stranded DNA virus. As a kind of parvovirus, H-1PV bound to the receptors on the surface of host cells and entered within endocytosis mediated by clathrin, inducing DNA damage and cell cycle arrest (92). The result of clinical trials showed that $\mathrm{H}-1 \mathrm{PV}$ could cross the BBB to reach the tumor and enhance the immunogenicity in tumor microenvironment $(93,94)$. Poliovirus was a kind of encapsidated viruses with a single strand RNA. Poliovirus infected tumor cells by binding the cell adhesion molecule CD155 expressed in GBM (95). The phase I clinical trial showed that PVS-RIPO (poliovirus-rhinovirus chimera) immunotherapy significantly improved the survival rate of GBM patients (96).

\section{GENE THERAPY}

Gene therapy achieved the purpose of treatment by delivering therapeutic genes or manipulating disease-related genes into target cells. Based on the related therapeutic strategies, gene therapy has been divided into suicide gene therapy, oncolytic viral gene therapy, tumor suppressor gene therapy, immuno-stimulatory therapy, and tumor microenvironmental regulation therapy (97, 98). Suicide gene therapy and oncolytic viral gene therapy have been described above. The main function of tumor suppressor genes included cell signal transduction and epigenetic regulation, negative regulation of cell cycle, negative regulator expression, regulation related to stem cell proliferation, and DNA mismatch repair. Studies have shown that Rb, p53, PTEN, CDKN2A, and other tumor suppressor genes played an important role in effective GBM inhibition. However, the related clinical trials on tumor suppressor gene therapy were limited. IFN- $\beta$ (interferon $\beta$ ) inhibited the growth and invasion of GBM with the effects of anti-tumor immune modulation, anti-proliferation, and antiangiogenesis (99). IFN- $\beta$ gene delivered by viral vectors showed a widespread expression and distribution in astrocytes and endothelial cells. A phase I clinical trial showed local inflammation and tumor necrosis in IFN- $\beta$ treatment (100). The intra-tumor injection of angiostatin could effectively inhibit tumor 
growth and vascularization $(101,102)$. Therefore, anti-angiogenic genes and tumor extracellular matrix regulatory genes made it possible to treat GBM via modulating tumor microenvironment.

\section{DISCUSSION}

Glioblastoma has been a common, highly aggressive, and heterogeneous brain tumor. The infiltration of GBM to the surrounding tissue made it impossible to eliminate by surgical intervention. The inefficient delivery of BBB reduced the therapeutic effect of chemotherapy. The abnormal vascularization promoted the proliferation of tumor cells. And immunosuppressive status in tumor microenvironment severely limited the anti-tumor response to GBM. Therefore, we urgently need new treatment strategies to face the challenges of this disease and improve the prognosis of patients. Gene therapy aimed to treat GBM by targeting and regulating oncogenes and tumor suppressor genes in tumor cells. The latest understanding of genetic material and molecular alteration provided an accurate theoretical basis for gene therapy. Due to the high transfection efficiency and the development of vector engineering techniques, viruses were widely used in the researches of GBM gene therapy. Viral vectors-mediated gene therapy could be combined with current treatment methods to improve therapeutic outcomes. The transmission of suicide genes has been evaluated in clinical trials to overcome the resistance of chemotherapy. HSV-tk and TOCA511 converted the prodrugs into active form and mediate the anti-tumor response. The transfection of sh-siRT1 vectors in CD133+ GBM cells significantly improved the resistance to radiotherapy. The extensive replication of oncolytic viruses in tumor cells, including ONYX-015, Delta-24, and PVS-RIPO, led to cytolysis and induced an anti-tumor immune response. Furthermore, the expression of cytokines could enhance the therapeutic effectiveness of viral vectors by improving antitumor immunity. However, there are still some concerns that need to resolve in viral gene therapy before its application in clinical therapy. The first is the transduction efficiency and expression stability of target genes. As we mentioned, the

\section{REFERENCES}

1. Tan A, Ashley D, López G, Malinzak M, Friedman H, Khasraw M. Management of Glioblastoma: State of the Art and Future Directions. CA: Cancer J Clin (2020) 70(4):299-312. doi: 10.3322/caac.21613

2. Nagle V, Henry K, Hertz C, Graham M, Campos C, Parada L, et al. Imaging Tumor-Infiltrating Lymphocytes in Brain Tumors With [Cu]Cu-NOTAAnti-CD8 PET. Clin Cancer Res an Off J Am Assoc Cancer Res (2021) 27:1958-66. doi: 10.1158/1078-0432.ccr-20-3243

3. Richard S. Explicating the Pivotal Pathogenic, Diagnostic, and Therapeutic Biomarker Potentials of Myeloid-Derived Suppressor Cells in Glioblastoma. Dis Markers (2020) 2020:8844313. doi: 10.1155/2020/8844313

4. Akter M, Lim J, Choi E, Han I. Non-Thermal Biocompatible Plasma Jet Induction of Apoptosis in Brain Cancer Cells. Cells (2021) 10(2):236. doi: $10.3390 /$ cells 10020236

5. Thomas A, Brennan C, DeAngelis L, Omuro A. Emerging Therapies for Glioblastoma. JAMA Neurol (2014) 71(11):1437-44. doi: 10.1001/ jamaneurol.2014.1701 expression level of receptors and the efficiency of membrane fusion affected the entry of the virus into tumor cells. How well the viruses entered the cells would determine the effectiveness of gene therapy. Non-replicative viruses, including adenoviral vectors, were not integrated into the host genome, the expression level of the transgenes might decrease with cell divisions. Secondly, viral vectors needed to be further optimized to improve tumor targeting especially in radiotherapy and chemotherapy-resistant GBM cells, and avoid entering normal cells. Multiforme implied that heterogeneity existed among the GBM cells within the same tumor. It has been necessary to explore the common mechanism of viral replication. Moreover, the use of engineering technology to eliminate the immunogenicity of virus was worth considering, which could avoid antiviral immunity. Currently, several preclinical trials and clinical trials have proved the safety of viral therapy. However, the effectiveness of its treatment in clinical trials was still unclear, so large clinical trials have been needed. Undeniably, viral gene therapy provided a new therapeutic approach and perspective in GBM treatment.

\section{CONCLUSION}

Viral gene therapy has shown strong therapeutic potential in GBM treatment. In the future, studies need to focus on the therapeutic efficacy and monitor adverse events before viral vectors widely use in clinical practice. Furthermore, the combination of viral gene therapy with other new treatment methods needs further research. Although the road ahead may be challenging, gene therapy has brought new hope for patients with GBM.

\section{AUTHOR CONTRIBUTIONS}

All authors listed have made a substantial, direct, and intellectual contribution to the work, and approved it for publication.

6. Batich K, Mitchell D, Healy P, Herndon J, Sampson J. Once, Twice, Three Times a Finding: Reproducibility of Dendritic Cell Vaccine Trials Targeting Cytomegalovirus in Glioblastoma. Clin Cancer Res an Off $J$ Am Assoc Cancer Res (2020) 26(20):5297-303. doi: 10.1158/1078-0432. ccr-20-1082

7. Vasilev A, Sofi R, Rahman R, Smith S, Teschemacher A, Kasparov S. Using Light for Therapy of Glioblastoma Multiforme (GBM). Brain Sci (2020) 10 (2):75. doi: 10.3390/brainsci10020075

8. Wick W, Osswald M, Wick A, Winkler F. Treatment of Glioblastoma in Adults. Ther Adv Neurological Disord (2018) 11:1756286418790452. doi: $10.1177 / 1756286418790452$

9. Birzu C, French P, Caccese M, Cerretti G, Idbaih A, Zagonel V, et al. Recurrent Glioblastoma: From Molecular Landscape to New Treatment Perspectives. Cancers (2020) 13(1):47. doi: 10.3390/cancers13010047

10. Cabrini G, Fabbri E, Lo Nigro C, Dechecchi MC, Gambari R. Regulation of Expression of O6-Methylguanine-DNA Methyltransferase and the Treatment of Glioblastoma (Review). Int J Oncol (2015) 47(2):417-28. doi: 10.3892/ ijo.2015.3026 
11. Lee SY. Temozolomide Resistance in Glioblastoma Multiforme. Genes Dis (2016) 3(3):198-210. doi: 10.1016/j.gendis.2016.04.007

12. Binabaj MM, Bahrami A, ShahidSales S, Joodi M, Joudi Mashhad M, Hassanian SM, et al. The Prognostic Value of MGMT Promoter Methylation in Glioblastoma: A Meta-Analysis of Clinical Trials. J Cell Physiol (2018) 233(1):378-86. doi: 10.1002/jcp.25896

13. Lu C, Shervington A. Chemoresistance in Gliomas. Mol Cell Biochem (2008) 312:71-80. doi: 10.1007/s11010-008-9722-8

14. Dréan A, Goldwirt L, Verreault M, Canney M, Schmitt C, Guehennec J, et al. Blood-Brain Barrier, Cytotoxic Chemotherapies and Glioblastoma. Expert Rev Neurother (2016) 16(11):1285-300. doi: 10.1080/14737175.2016.1202761

15. Da Ros M, De Gregorio V, Iorio AL, Giunti L, Guidi M, de Martino M, et al. Glioblastoma Chemoresistance: The Double Play by Microenvironment and Blood-Brain Barrier. Int J Mol Sci (2018) 19(10):2879. doi: 10.3390/ ijms19102879

16. Vengoji R, Ponnusamy MP, Rachagani S, Mahapatra S, Batra SK, Shonka N, et al. Novel Therapies Hijack the Blood-Brain Barrier to Eradicate Glioblastoma Cancer Stem Cells. Carcinogenesis (2019) 40(1):2-14. doi: 10.1093/carcin/bgy171

17. Pointer KB, Clark PA, Zorniak M, Alrfaei BM, Kuo JS. Glioblastoma Cancer Stem Cells: Biomarker and Therapeutic Advances. Neurochemistry Int (2014) 71:1-7. doi: 10.1016/j.neuint.2014.03.005

18. Alifieris C, Trafalis DT. Glioblastoma Multiforme: Pathogenesis and Treatment. Pharmacol Ther (2015) 152:63-82. doi: 10.1016/j.pharmthera.2015.05.005

19. Bernstock JD, Mooney JH, Ilyas A, Chagoya G, Estevez-Ordonez D, Ibrahim A, et al. Molecular and Cellular Intratumoral Heterogeneity in Primary Glioblastoma: Clinical and Translational Implications. J Neurosurgery (2019) 133:611-946. doi: 10.3171/2019.5.jns19364

20. Thakkar JP, Dolecek TA, Horbinski C, Ostrom QT, Lightner DD, BarnholtzSloan JS, et al. Epidemiologic and Molecular Prognostic Review of Glioblastoma. Cancer epidemiology Biomarkers Prev Publ Am Assoc Cancer Research cosponsored by Am Soc Prev Oncol (2014) 23(10):198596. doi: 10.1158/1055-9965.epi-14-0275

21. Riley MM, San P, Lok E, Swanson KD, Wong ET. The Clinical Application of Tumor Treating Fields Therapy in Glioblastoma. J Visualized Experiments JoVE (2019) 146. doi: 10.3791/58937

22. Benitez J, Finlay D, Castanza A, Parisian A, Ma J, Longobardi C, et al. Pten Deficiency Leads to Proteasome Addiction, a Novel Vulnerability in Glioblastoma. Neuro-Oncology (2021). doi: 10.1093/neuonc/noab001

23. Roux A, Peeters S, Zanello M, Bou Nassif R, Abi Lahoud G, Dezamis E, et al. Extent of Resection and Carmustine Wafer Implantation Safely Improve Survival in Patients With a Newly Diagnosed Glioblastoma: A Single Center Experience of the Current Practice. J Neuro-Oncology (2017) 135(1):83-92. doi: 10.1007/s11060-017-2551-4

24. Akiyama Y, Kimura Y, Enatsu R, Mikami T, Wanibuchi M, Mikuni N. Advantages and Disadvantages of Combined Chemotherapy With Carmustine Wafer and Bevacizumab in Patients With Newly Diagnosed Glioblastoma: A Single-Institutional Experience. World Neurosurgery (2018) 113:e508-e14. doi: 10.1016/j.wneu.2018.02.070

25. Anthony C, Mladkova-Suchy N, Adamson D. The Evolving Role of Antiangiogenic Therapies in Glioblastoma Multiforme: Current Clinical Significance and Future Potential. Expert Opin investigational Drugs (2019) 28(9):787-97. doi: 10.1080/13543784.2019.1650019

26. Xiao ZZ, Wang ZF, Lan T, Huang WH, Zhao YH, Ma C, et al. Carmustine as a Supplementary Therapeutic Option for Glioblastoma: A Systematic Review and Meta-Analysis. Front Neurol (2020) 11:1036. doi: 10.3389/fneur.2020.01036

27. Batash R, Asna N, Schaffer P, Francis N, Schaffer M. Glioblastoma Multiforme, Diagnosis and Treatment; Recent Literature Review. Curr medicinal Chem (2017) 24(27):3002-9. doi: 10.2174/0929867324666170516123206

28. Burri SH, Gondi V, Brown PD, Mehta MP. The Evolving Role of Tumor Treating Fields in Managing Glioblastoma: Guide for Oncologists. Am J Clin Oncol (2018) 41(2):191-6. doi: 10.1097/coc.0000000000000395

29. Jovčevska I. Sequencing the Next Generation of Glioblastomas. Crit Rev Clin Lab Sci (2018) 55(4):264-82. doi: 10.1080/10408363.2018.1462759

30. Le Rhun E, Preusser M, Roth P, Reardon DA, van den Bent M, Wen P, et al. Molecular Targeted Therapy of Glioblastoma. Cancer Treat Rev (2019) 80:101896. doi: 10.1016/j.ctrv.2019.101896
31. Bansal K, Engelhard HH. Gene Therapy for Brain Tumors. Curr Oncol Rep (2000) 2(5):463-72. doi: 10.1007/s11912-000-0067-z

32. Kroeger KM, Muhammad AK, Baker GJ, Assi H, Wibowo MK, Xiong W, et al. Gene Therapy and Virotherapy: Novel Therapeutic Approaches for Brain Tumors. Discovery Med (2010) 10(53):293-304.

33. Assi H, Candolfi M, Baker G, Mineharu Y, Lowenstein PR, Castro MG. Gene Therapy for Brain Tumors: Basic Developments and Clinical Implementation. Neurosci Lett (2012) 527(2):71-7. doi: 10.1016/ j.neulet.2012.08.003

34. Immidisetti A, Nwagwu C, Adamson D, Patel N, Carbonell A. Clinically Explored Virus-Based Therapies for the Treatment of Recurrent High-Grade Glioma in Adults. Biomedicines (2021) 9(2):138. doi: 10.3390/ biomedicines 9020138

35. Saha D, Martuza RL, Rabkin SD. Oncolytic Herpes Simplex Virus Immunovirotherapy in Combination With Immune Checkpoint Blockade to Treat Glioblastoma. Immunotherapy (2018) 10(9):779-86. doi: 10.2217/ imt-2018-0009

36. Di Meco F, Benedetti S, Colombo MP, Finocchiaro G. Perspectives for the Gene Therapy of Malignant Gliomas by Suicide Gene Transfer. J neurosurgical Sci (1997) 41(3):227-34.

37. Tai CK, Kasahara N. Replication-Competent Retrovirus Vectors for Cancer Gene Therapy. Front Bioscience (2008) 13:3083-95. doi: 10.2741/2910

38. Culver KW, Ram Z, Wallbridge S, Ishii H, Oldfield EH, Blaese RM. In Vivo Gene Transfer With Retroviral Vector-Producer Cells for Treatment of Experimental Brain Tumors. Science (5063) 1992) 256:1550-2. doi: 10.1126/ science. 1317968

39. Haddad AF, Young JS, Mummaneni NV, Kasahara N, Aghi MK. Immunologic Aspects of Viral Therapy for Glioblastoma and Implications for Interactions With Immunotherapies. J Neuro-Oncology (2021) 152:1-13. doi: 10.1007/s11060-020-03684-5

40. Rainov NG. A Phase III Clinical Evaluation of Herpes Simplex Virus Type 1 Thymidine Kinase and Ganciclovir Gene Therapy as an Adjuvant to Surgical Resection and Radiation in Adults With Previously Untreated Glioblastoma Multiforme. Hum Gene Ther (2000) 11(17):2389-401. doi: 10.1089/ 104303400750038499

41. Ram Z, Culver KW, Oshiro EM, Viola JJ, DeVroom HL, Otto E, et al. Therapy of Malignant Brain Tumors by Intratumoral Implantation of Retroviral Vector-Producing Cells. Nat Med (1997) 3(12):1354-61. doi: 10.1038/nm1297-1354

42. Perez OD, Logg CR, Hiraoka K, Diago O, Burnett R, Inagaki A, et al. Design and Selection of Toca 511 for Clinical Use: Modified Retroviral Replicating Vector With Improved Stability and Gene Expression. Mol Ther J Am Soc Gene Ther (2012) 20(9):1689-98. doi: 10.1038/mt.2012.83

43. Hogan DJ, Zhu JJ, Diago OR, Gammon D, Haghighi A, Lu G, et al. Molecular Analyses Support the Safety and Activity of Retroviral Replicating Vector Toca 511 in Patients. Clin Cancer Res (2018) 24 (19):4680-93. doi: 10.1158/1078-0432.ccr-18-0619

44. Takahashi M, Valdes G, Hiraoka K, Inagaki A, Kamijima S, Micewicz E, et al. Radiosensitization of Gliomas by Intracellular Generation of 5-Fluorouracil Potentiates Prodrug Activator Gene Therapy With a Retroviral Replicating Vector. Cancer Gene Ther (2014) 21(10):405-10. doi: 10.1038/cgt.2014.38

45. Hiraoka K, Inagaki A, Kato Y, Huang TT, Mitchell LA, Kamijima S, et al. Retroviral Replicating Vector-Mediated Gene Therapy Achieves Long-Term Control of Tumor Recurrence and Leads to Durable Anticancer Immunity. Neuro Oncol (2017) 19(7):918-29. doi: 10.1093/neuonc/nox038

46. Mitchell LA, Lopez Espinoza F, Mendoza D, Kato Y, Inagaki A, Hiraoka K, et al. Toca 511 Gene Transfer and Treatment With the Prodrug, 5Fluorocytosine, Promotes Durable Antitumor Immunity in a Mouse Glioma Model. Neuro Oncol (2017) 19(7):930-9. doi: 10.1093/neuonc/ nox 037

47. Cloughesy TF, Landolfi J, Hogan DJ, Bloomfield S, Carter B, Chen CC, et al. Phase 1 Trial of Vocimagene Amiretrorepvec and 5-Fluorocytosine for Recurrent High-Grade Glioma. Sci Trans Med (2016) 8(341):341ra75. doi: 10.1126/scitranslmed.aad9784

48. Cloughesy TF, Petrecca K, Walbert T, Butowski N, Salacz M, Perry J, et al. Effect of Vocimagene Amiretrorepvec in Combination With Flucytosine Vs Standard of Care on Survival Following Tumor Resection in Patients With 
Recurrent High-Grade Glioma: A Randomized Clinical Trial. JAMA Oncol (2020) 6(12):1939-46. doi: 10.1001/jamaoncol.2020.3161

49. Lesnik EA, Sampath R, Ecker DJ. Rev Response Elements (RRE) in Lentiviruses: An Rnamotif Algorithm-Based Strategy for RRE Prediction. Medicinal Res Rev (2002) 22(6):617-36. doi: 10.1002/med.10027

50. Moreira AS, Cavaco DG, Faria TQ, Alves PM, Carrondo MJT, Peixoto C. Advances in Lentivirus Purification. Biotechnol J (2021) 16(1):e2000019. doi: 10.1002/biot.202000019

51. McCarron A, Donnelley M, McIntyre C, Parsons D. Challenges of UpScaling Lentivirus Production and Processing. J Biotechnol (2016) 240:2330. doi: 10.1016/j.jbiotec.2016.10.016

52. Manikandan C, Kaushik A, Sen D. Viral Vector: Potential Therapeutic for Glioblastoma Multiforme. Cancer Gene Ther (2020) 27(5):270-9. doi: 10.1038/s41417-019-0124-8

53. Kock N, Kasmieh R, Weissleder R, Shah K. Tumor Therapy Mediated by Lentiviral Expression of Shbcl-2 and S-TRAIL. Neoplasia (New York NY) (2007) 9(5):435-42. doi: 10.1593/neo.07223

54. Chang CJ, Hsu CC, Yung MC, Chen KY, Tzao C, Wu WF, et al. Enhanced Radiosensitivity and Radiation-Induced Apoptosis in Glioma CD133Positive Cells by Knockdown of Sirt1 Expression. Biochem Biophys Res Commun (2009) 380(2):236-42. doi: 10.1016/j.bbrc.2009.01.040

55. Luan Y, Zhang S, Zuo L, Zhou L. Overexpression of Mir-100 Inhibits Cell Proliferation, Migration, and Chemosensitivity in Human Glioblastoma Through FGFR3. OncoTargets Ther (2015) 8:3391-400. doi: 10.2147/ ott.s85677

56. Sun T, Patil R, Galstyan A, Klymyshyn D, Ding H, Chesnokova A, et al. Blockade of a Laminin-411-Notch Axis With CRISPR/Cas9 or a Nanobioconjugate Inhibits Glioblastoma Growth Through TumorMicroenvironment Cross-Talk. Cancer Res (2019) 79(6):1239-51. doi: 10.1158/0008-5472.can-18-2725

57. Sánchez-Hernández L, Hernández-Soto J, Vergara P, González RO, Segovia J. Additive Effects of the Combined Expression of Soluble Forms of GAS1 and PTEN Inhibiting Glioblastoma Growth. Gene Ther (2018) 25(6):439-49. doi: 10.1038/s41434-018-0020-0

58. Hall K, Blair Zajdel ME, Blair GE. Unity and Diversity in the Human Adenoviruses: Exploiting Alternative Entry Pathways for Gene Therapy. Biochem J (2010) 431(3):321-36. doi: 10.1042/bj20100766

59. Yang TC, Maluf NK. Characterization of the Non-Specific DNA Binding Properties of the Adenoviral Iva2 Protein. Biophys Chem (2014) 193-194:18. doi: 10.1016/j.bpc.2014.06.005

60. Volpers C, Kochanek S. Adenoviral Vectors for Gene Transfer and Therapy. J Gene Med (2004) 6 Suppl 1:S164-71. doi: 10.1002/jgm.496

61. Bergelson JM, Cunningham JA, Droguett G, Kurt-Jones EA, Krithivas A, Hong JS, et al. Isolation of a Common Receptor for Coxsackie B Viruses and Adenoviruses 2 and 5. Science (5304) 1997) 275:1320-3. doi: 10.1126/ science. 275.5304 .1320

62. Zhang Y, Bergelson JM. Adenovirus Receptors. J Virol (2005) 79(19):1212531. doi: 10.1128/jvi.79.19.12125-12131.2005

63. Stasiak AC, Stehle T. Human Adenovirus Binding to Host Cell Receptors: A Structural View. Med Microbiol Immunol (2020) 209(3):325-33. doi: 10.1007/s00430-019-00645-2

64. Castro MG, Candolfi M, Wilson TJ, Calinescu A, Paran C, Kamran N, et al. Adenoviral Vector-Mediated Gene Therapy for Gliomas: Coming of Age. Expert Opin Biol Ther (2014) 14(9):1241-57. doi: 10.1517/14712598.2014.915307

65. Kochanek S. High-Capacity Adenoviral Vectors for Gene Transfer and Somatic Gene Therapy. Hum Gene Ther (1999) 10(15):2451-9. doi: 10.1089/10430349950016807

66. Nandi S, Lesniak M. Adenoviral Virotherapy for Malignant Brain Tumors. Expert Opin Biol Ther (2009) 9(6):737-47. doi: 10.1517/14712590902988451

67. McCormick F. Interactions Between Adenovirus Proteins and the P53 Pathway: The Development of ONYX-015. Semin Cancer Biol (2000) 10 (6):453-9. doi: 10.1006/scbi.2000.0336

68. Rius-Rocabert S, García-Romero N, García A, Ayuso-Sacido A, Nistal-Villan E. Oncolytic Virotherapy in Glioma Tumors. Int J Mol Sci (2020) 21 (20):7604. doi: 10.3390/ijms 21207604

69. Chiocca EA, Abbed KM, Tatter S, Louis DN, Hochberg FH, Barker F, et al. A Phase I Open-Label, Dose-Escalation, Multi-Institutional Trial of Injection With an E1B-Attenuated Adenovirus, ONYX-015, Into the
Peritumoral Region of Recurrent Malignant Gliomas, in the Adjuvant Setting. Mol Ther J Am Soc Gene Ther (2004) 10(5):958-66. doi: 10.1016/ j.ymthe.2004.07.021

70. Fueyo J, Gomez-Manzano C, Alemany R, Lee PS, McDonnell TJ, Mitlianga $\mathrm{P}$, et al. A Mutant Oncolytic Adenovirus Targeting the Rb Pathway Produces Anti-Glioma Effect in Vivo. Oncogene (2000) 19(1):2-12. doi: 10.1038/ sj.onc. 1203251

71. Philbrick B, Adamson DC. DNX-2401: An Investigational Drug for the Treatment of Recurrent Glioblastoma. Expert Opin Investig Drugs (2019) 28 (12):1041-9. doi: 10.1080/13543784.2019.1694000

72. Lamfers ML, Grill J, Dirven CM, Van Beusechem VW, Geoerger B, Van Den Berg J, et al. Potential of the Conditionally Replicative Adenovirus Ad5Delta24RGD in the Treatment of Malignant Gliomas and Its Enhanced Effect With Radiotherapy. Cancer Res (2002) 62(20):5736-42.

73. Ahmad I, Wilson DW. HSV-1 Cytoplasmic Envelopment and Egress. Int $J$ Mol Sci (2020) 21(17):5969. doi: 10.3390/ijms21175969

74. Grandi P, Peruzzi P, Reinhart B, Cohen JB, Chiocca EA, Glorioso JC. Design and Application of Oncolytic HSV Vectors for Glioblastoma Therapy. Expert Rev Neurother (2009) 9(4):505-17. doi: 10.1586/ern.09.9

75. Streby KA, Geller JI, Currier MA, Warren PS, Racadio JM, Towbin AJ, et al. Intratumoral Injection of HSV1716, an Oncolytic Herpes Virus, is Safe and Shows Evidence of Immune Response and Viral Replication in Young Cancer Patients. Clin Cancer Res (2017) 23(14):3566-74. doi: 10.1158/ 1078-0432.ccr-16-2900

76. Rampling R, Cruickshank G, Papanastassiou V, Nicoll J, Hadley D, Brennan D, et al. Toxicity Evaluation of Replication-Competent Herpes Simplex Virus (ICP 34.5 Null Mutant 1716) in Patients With Recurrent Malignant Glioma. Gene Ther (2000) 7(10):859-66. doi: 10.1038/sj.gt. 3301184

77. Harrow S, Papanastassiou V, Harland J, Mabbs R, Petty R, Fraser M, et al. HSV1716 Injection Into the Brain Adjacent to Tumour Following Surgical Resection of High-Grade Glioma: Safety Data and Long-Term Survival. Gene Ther (2004) 11(22):1648-58. doi: 10.1038/sj.gt.3302289

78. Cassady KA, Bauer DF, Roth J, Chambers MR, Shoeb T, Coleman J, et al. Pre-Clinical Assessment of C134, a Chimeric Oncolytic Herpes Simplex Virus, in Mice and Non-Human Primates. Mol Ther Oncolytics (2017) 5:110. doi: 10.1016/j.omto.2017.02.001

79. Cinatl J Jr, Michaelis M, Driever PH, Cinatl J, Hrabeta J, Suhan T, et al. Multimutated Herpes Simplex Virus G207 is a Potent Inhibitor of Angiogenesis. Neoplasia (New York NY) (2004) 6(6):725-35. doi: 10.1593/ neo.04265

80. Markert JM, Liechty PG, Wang W, Gaston S, Braz E, Karrasch M, et al. Phase Ib Trial of Mutant Herpes Simplex Virus G207 Inoculated Pre-and Post-Tumor Resection for Recurrent GBM. Mol Ther J Am Soc Gene Ther (2009) 17(1):199-207. doi: 10.1038/mt.2008.228

81. Markert JM, Razdan SN, Kuo HC, Cantor A, Knoll A, Karrasch M, et al. A Phase 1 Trial of Oncolytic HSV-1, G207, Given in Combination With Radiation for Recurrent GBM Demonstrates Safety and Radiographic Responses. Mol Ther J Am Soc Gene Ther (2014) 22(5):1048-55. doi: $10.1038 / \mathrm{mt} .2014 .22$

82. Chiocca EA, Nakashima H, Kasai K, Fernandez SA, Oglesbee M. Preclinical Toxicology of Rqnestin34.5v.2: An Oncolytic Herpes Virus With Transcriptional Regulation of the ICP34.5 Neurovirulence Gene. Mol Ther Methods Clin Dev (2020) 17:871-93. doi: 10.1016/j.omtm.2020.03.028

83. Bartlett DL, Liu Z, Sathaiah M, Ravindranathan R, Guo Z, He Y, et al. Oncolytic Viruses as Therapeutic Cancer Vaccines. Mol Cancer (2013) 12 (1):103. doi: 10.1186/1476-4598-12-103

84. Foreman PM, Friedman GK, Cassady KA, Markert JM. Oncolytic Virotherapy for the Treatment of Malignant Glioma. Neurother J Am Soc Exp Neurother (2017) 14(2):333-44. doi: 10.1007/s13311-017-0516-0

85. Breitbach CJ, Paterson JM, Lemay CG, Falls TJ, McGuire A, Parato KA, et al. Targeted Inflammation During Oncolytic Virus Therapy Severely Compromises Tumor Blood Flow. Mol Ther J Am Soc Gene Ther (2007) 15(9):1686-93. doi: 10.1038/sj.mt.6300215

86. Workenhe ST, Mossman KL. Oncolytic Virotherapy and Immunogenic Cancer Cell Death: Sharpening the Sword for Improved Cancer Treatment Strategies. Mol Ther J Am Soc Gene Ther (2014) 22(2):251-6. doi: 10.1038/ mt.2013.220 
87. Chiocca EA, Rabkin SD. Oncolytic Viruses and Their Application to Cancer Immunotherapy. Cancer Immunol Res (2014) 2(4):295-300. doi: 10.1158/ 2326-6066.cir-14-0015

88. Biederer C, Ries S, Brandts CH, McCormick F. Replication-Selective Viruses for Cancer Therapy. J Mol Med (Berlin Germany) (2002) 80(3):163-75. doi: 10.1007/s00109-001-0295-1

89. Forsyth P, Roldán G, George D, Wallace C, Palmer CA, Morris D, et al. A Phase I Trial of Intratumoral Administration of Reovirus in Patients With Histologically Confirmed Recurrent Malignant Gliomas. Mol Ther J Am Soc Gene Ther (2008) 16(3):627-32. doi: 10.1038/sj.mt.6300403

90. Samson A, Scott KJ, Taggart D, West EJ, Wilson E, Nuovo GJ, et al. Intravenous Delivery of Oncolytic Reovirus to Brain Tumor Patients Immunologically Primes for Subsequent Checkpoint Blockade. Sci Trans Med (2018) 10(422):7577. doi: 10.1126/scitranslmed.aam7577

91. Thorne SH, Bartlett DL, Kirn DH. The Use of Oncolytic Vaccinia Viruses in the Treatment of Cancer: A New Role for an Old Ally? Curr Gene Ther (2005) 5(4):429-43. doi: 10.2174/1566523054546215

92. Vihinen-Ranta M, Suikkanen S, Parrish CR. Pathways of Cell Infection by Parvoviruses and Adeno-Associated Viruses. J Virol (2004) 78(13):6709-14. doi: 10.1128/jvi.78.13.6709-6714.2004

93. Geletneky K, Hajda J, Angelova AL, Leuchs B, Capper D, Bartsch AJ, et al. Oncolytic H-1 Parvovirus Shows Safety and Signs of Immunogenic Activity in a First Phase I/Iia Glioblastoma Trial. Mol Ther J Am Soc Gene Ther (2017) 25(12):2620-34. doi: 10.1016/j.ymthe.2017.08.016

94. Angelova AL, Barf M, Geletneky K, Unterberg A, Rommelaere J. Immunotherapeutic Potential of Oncolytic H-1 Parvovirus: Hints of Glioblastoma Microenvironment Conversion Towards Immunogenicity. Viruses (2017) 9(12):382. doi: 10.3390/v9120382

95. Merrill MK, Bernhardt G, Sampson JH, Wikstrand CJ, Bigner DD, Gromeier M. Poliovirus Receptor CD155-Targeted Oncolysis of Glioma. Neuro Oncol (2004) 6(3):208-17. doi: 10.1215/s1152851703000577

96. Desjardins A, Gromeier M, Herndon JE,2, Beaubier N, Bolognesi DP, Friedman AH, et al. Recurrent Glioblastoma Treated With Recombinant Poliovirus. New Engl J Med (2018) 379(2):150-61. doi: 10.1056/ NEJMoa1716435
97. Kamran N, Calinescu A, Candolfi M, Chandran M, Mineharu Y, Asad A, et al. Recent Advances and Future of Immunotherapy for Glioblastoma. Expert Opin Biol Ther (2016) 16(10):1245-64. doi: 10.1080/14712598. 2016.1212012

98. Zhang H, Wang R, Yu Y, Liu J, Luo T, Fan F. Glioblastoma Treatment Modalities Besides Surgery. J Cancer (2019) 10(20):4793-806. doi: 10.7150/ jca. 32475

99. GuhaSarkar D, Su Q, Gao G, Sena-Esteves M. Systemic AAV9-Ifn $\beta$ Gene Delivery Treats Highly Invasive Glioblastoma. Neuro-Oncology (2016) 18 (11):1508-18. doi: 10.1093/neuonc/now097

100. Yoshida J, Mizuno M, Fujii M, Kajita Y, Nakahara N, Hatano M, et al. Human Gene Therapy for Malignant Gliomas (Glioblastoma Multiforme and Anaplastic Astrocytoma) by in Vivo Transduction With Human Interferon Beta Gene Using Cationic Liposomes. Hum Gene Ther (2004) 15(1):77-86. doi: 10.1089/10430340460732472

101. Tanaka T, Cao Y, Folkman J, Fine H. Viral Vector-Targeted Antiangiogenic Gene Therapy Utilizing an Angiostatin Complementary DNA. Cancer Res (1998) 58(15):3362-9.

102. Szentirmai O, Baker C, Bullain S, Lin N, Takahashi M, Folkman J, et al. Successful Inhibition of Intracranial Human Glioblastoma Multiforme Xenograft Growth Via Systemic Adenoviral Delivery of Soluble Endostatin and Soluble Vascular Endothelial Growth Factor Receptor-2: Laboratory Investigation. J neurosurgery (2008) 108(5):979-88. doi: 10.3171/jns/2008/ $108 / 5 / 0979$

Conflict of Interest: The authors declare that the research was conducted in the absence of any commercial or financial relationships that could be construed as a potential conflict of interest.

Copyright (C) 2021 Li, Wang, Wang, Cao, Wang and Zhao. This is an open-access article distributed under the terms of the Creative Commons Attribution License (CC BY). The use, distribution or reproduction in other forums is permitted, provided the original author(s) and the copyright owner(s) are credited and that the original publication in this journal is cited, in accordance with accepted academic practice. No use, distribution or reproduction is permitted which does not comply with these terms. 